\title{
KONTRIBUSI KELENTUKAN PINGGANG DAN POWER OTOT LENGAN PADA KETERAMPILAN STUTZ SENAM LANTAI
}

\section{Soni Kurniawan}

PENJAS FKIP UNIB, e-mail: Sonikurniawan11.sk@gmail.com

\author{
Tono Sugihartono \\ Univesitas Bengkulu \\ Yarmani \\ Universitas Bengkulu \\ Defliyanto \\ Universitas Bengkulu
}

\begin{abstract}
Abstrak
Penelitian ini bertujuan untuk mengetahui kontribusi kelentukan pinggang dan power otot lengan terhadap keterampilan Stutz senam lantai siswa SMP Negeri 17 Kota Bengkulu. Adapun rumusan masalah dalam penelitian, apakah ada hubungan kelentukan pinggang terhadap keterampilan Stutz, hubungan power otot lengan terhadap keterampilan Stutz, hubungan kelentukan pinggang dan power otot lengan terhadap keterampilan Stutz, Serta mengetahui besar kontribusi kelentukan pinggang dan power otot lengan terhadap keterampilan Stutz. Penelitian ini dilakukan di SMP negeri 17 kota bengkulu. Metode penelitian yang digunakan metode korelasi dengan statistik product moment dan korelasi ganda, penelitian ini secara objektif terhadap sampel 30 orang siswa SMP negeri 17 kota Bengkulu yang diambil dengan teknik Proportionate Stratified Random Sampling. Adapun hasil $r_{\text {hitung }}=0,67>r_{\text {tabel }}$ $=0,361$, dengan pengajian hipotesis kerja $(\mathrm{Ha})$ diterima artinya terdapat hubungan yang berarti antara $X_{1}$ dan $X_{2}$ dengan $Y$. sehingga dapat disimpulkan bahwa ada kontribusi antara kelentukan pinggang dan power otot lengan terhadap keterampilan Stutz sebesar $44,89 \%$.
\end{abstract}

Kata kunci: Kelentukan Pinggang, Power Otot Lengan dan Keterampilan Stutz

\section{Abstract}


This research aims to determine the contribution of the flexibility of waist and the power of muscle through Stutz gymnastics floor skills of the students of SMP Negeri 17 Bengkulu city. The research problem were, whether there was a relationship between the flexibility of waist, the power of arm muscle, toward Stutz skill, and to find the contributions of the flexibility of waist and the power of arm muscle toward Stutz skill. This research would be done at SMP Negeri 17 Bengkulu city. The method of this research were correlation method with statistical product moment and multiple correlation this research objectively to the sample of 30 students at SMP Negeri 17 of Bengkulu city which was taken by proportionate stratified Random Sampling Technique. The results of the data showed $r_{\text {hitung }}=0,67>r_{\text {tabel }}=$ 0,361 , with a recitation working hypothesis $(\mathrm{Ha})$ was accepted, means that there ia a significant relationship between $X_{1}$ and $X_{2}$ with $Y$. it can be conclude that there was a contribution between waist flexibility and the power of arm muscle toward Stutz skill showed the percentage of $44.89 \%$.

Keywords: flexibility Waist, Arm Muscle Power and Skills Stutz

\section{PENDAHULUAN}

Senam

merupakan

kegiatan fisik yang paling kaya struktur gerakannya. Dilihat dari taksonomi gerak umum, senam bisa secara lengkap diwakili oleh gerakgerak dasar yang membangun pola gerak yang lengkap, dari mulai gerakan lokomotor (berpindah tempat), non lokomotor (tidak berpindah tempat), dan manipulatif (memanipulasi subjek) Mahendra (2001:21).

Peter $\mathrm{H}$. Werner dalam Agus Mahendra (2001:9) mengatakan Senam dapat diartikan sebagai bentuk latihan tubuh pada lantai atau pada alat yang dirancang untuk meningkatkan daya tahan, kekuatan, kelentukan, kelincahan, koordinasi, serta kontrol tubuh. Banyak cabang olahraga senam seperti senam artistik, aerobik, ketangkasan dan lainya. Pembelajaran senam lantai terdapat berbagai macam gerakan senam lantai salah satu diantaranya gerakan Stutz.

Gerakan Stutz dilakukan dengan sikap awalan duduk berlunjur, berjongkok atau dari sikap berdiri. Pada gerakan Stutz pesenam harus memiliki kelincahan tubuh yang baik agar dapat melakukan gerakan maksimal. Selain kelincahan tubuh pesenam juga harus melatih gerakan keseimbangan tubuh, tolakan dan lemparan kedua kaki. 
Sebelum melakukan gerakan Stutz pesenam harus memperhatikan dasar-dasar dalam melakukan keterampilan yaitu kelenturan, keseimbangan dan kelincahan.

salah satu ciri khusus dari pesenam adalah memiliki kelentukan yang tinggi pada hampir seluruh persendiannya. Menurut Widiastuti (2011:153) Kelentukan (flexibility) adalah kemampuan sendi untuk melakukan gerak dalam ruang gerak sendi secara maksimal. Kelenturan menunjukan besarnya pergerakan sendi secara maksimal sesuai dengan kemungkinan gerakan. Kelentukan pinggang pada keterampilan Stutz digunakan untuk memberikan kesempurnaan gerak. Untuk tingkat kelentukan pinggang yang baik akan dapat melakukan gerakan Stutz yang baik pula, gerakan yang dilakukan lebih efisien, efektif, dan harmonis.

Gerakan senam power otot lengan juga diperlukan pada gerakan Stutz. Karena Power atau daya ledak merupakan suatu komponen biomotorik dalam kegiatan olahraga salah satunya olahraga senam, karena daya ledak akan menentukan seberapa kuat dan seberapa cepat pesenam dalam melakukan gerakan Stutz. Menurut Harsono dalam Wina
Nurasifa Fajriani (2011:16) Mengatakan bahwa power adalah kemampuan otot untuk menggerakkan kekuatan maksimal dalam waktu yang sangat cepat. Maka Power otot lengan yang baik pada keterampilan Stutz akan membantu untuk mengangkat tubuh yang secara cepat sehingga akan mempermudah dalam melakukan gerakan Stutz, karena power otot lengan merupakan titik berat badan dalam melakukan gerakan Stutz.

Jadi dalam gerakan Stutz pada senam lantai, kelentukan pinggang dan power otot lengan sangat memberikan sumbangan untuk melakukan gerakan Stutz agar mendapatakan hasil gerakan yang baik.

Rumusan masalah dalam penelitian ini yaitu: 1. Apakah ada hubungan kelentukan pinggang terhadap keterampilan Stutz pada senam lantai siswa SMP Negeri 17 Kota Bengkulu? 2. Apakah ada hubungan power otot lengan terhadap keterampilan Stutz pada senam lantai siswa SMP Negeri 17 Kota Bengkulu? 3. Apakah ada hubungan kelentukan pinggang dan kemampuan power otot lengan terhadap keterampilan Stutz pada senam lantai siswa SMP Negeri 17 Kota Bengkulu? 4. Berapakah besar sumbangan 
(kontribusi) kelentukan pinggang dan power otot lengan terhadap keterampilan Stutz pada senam lantai siswa SMP Negeri 17 Kota Bengkulu?

Tujuan kegiatan penelitian ini adalah: $1 . \quad$ Untuk mengetahui hubungan kelentukan pinggang terhadap keterampilan Stutz. 2. Untuk mengetahui hubungan power otot lengan terhadap keterampilan Stutz. 3. Untuk mengetahui ada hubungan yang signifikan antara kelentukan pinggang dan power otot lengan terhadap keterampilan Stutz. 4. Untuk mengetahui berapa besar sumbangan (kontribusi) kelentukan pinggang dan power otot lengan terhadap keterampilan Stutz.

\section{METODE}

Penelitian ini merupakan penelitian yang menggunakan uji korelasi (correlation research), yang bertujuan untuk mengetahui hubungan antara variabel bebas dan variable terikat. Menurut Arikunto (2010:313) "penelitian korelasi bertujuan untuk menemukan ada tidaknya hubungan dan apabila ada, berapa eratnya hubungan serta berarti atau tidak hubungan itu". Hal tersebut sama yang disampaikan menurut Endang Widi Winarni (2011:46) “Penelitian korelasional adalah penelitian yang akan melihat hubungan antara variabel atau beberapa variabel dengan variabel lain".dan analisis kontribusi besaran pengaruh variabel bebas secara simultan terhadap variabel terikat. Dengan populasi terdapat 106 orang sedangkan sampel yang dilakukan sebanyak 30 orang.

Sugiyono (2006: 42) "variabel penelitian adalah suatu atribut atau sifat atau nilai dari orang, obyek atau kegiatan yang mempunyai variasi tertentu yang ditetapkan oleh peneliti untuk dipelajari dan kemudian ditarik kesimpulannya". Variabel yang digunakan dalam penelitian ini yaitu variabel bebas dan variabel terikat. Adapun variabel bebas dalam penelitian ini yaitu kelentukan pinggang dan power otot lengan, sedangkan variabel terikat yaitu keterampilan Stutz pada senam lantai.

Analisis data Sebelum mencari hubungan antara kelentukan pinggang $\left(X_{1}\right)$ dan power otot lengan $\left(X_{2}\right)$ terhadap keterampilan Stutz (Y) pada senam lantai maka dilanjutkan uji statistik korelasional. Sebelum dilakukan uji statistic korelasi terlebih dahulu dilakukan uji normalitas dan uji homogenitas sebagai uji prasyarat. 


\section{HASIL DAN PEMBAHASAN Hasil}

Tes Kelentukan Pinggang

30 Siswa SMP Negeri 17 Kota Bengkulu sebanyak 5 orang siswa (17\%) memiliki kategori nilai 7-9 dan sebanyak 7 orang siswa (23\%) dan memiliki katagori nilai 10 - 12 dan sebanyak 8 orang siswa $(27 \%)$ memiliki katagori nilai 13 - 15 dan sebanyak 5 orang siswa (17\%) memiliki katagori nilai 16 - 18 dan sebanyak 4 orang siswa (13\%) memiliki katagori nilai 19 - 21 dan sebanyak 1 orang siswa (3\%) memiliki katagori nilai 22 24.

Hasil Tes Power Otot Lengan $\left(X_{2}\right)$

30 Siswa SMP Negeri 17 Kota Bengkulu sebanyak 4 orang siswa (13\%) memiliki kategori nilai 13-15 dan sebanyak 3 orang siswa (10\%) dan memiliki katagori nilai 16-18 dan sebanyak 4 orang siswa (13\%) memiliki katagori nilai 19-21 dan sebanyak 8 orang siswa $(27 \%)$ memiliki katagori nilai 22-24 dan sebanyak 7 orang siswa (24\%) memiliki katagori nilai 25-27 dan sebanyak 4 orang siswa (13\%) memiliki katagori nilai 28-30.

Hasil Tes Keterampilan Stutz (Y)
30 Siswa SMP Negeri 17 Kota Bengkulu sebanyak 2 orang siswa (6\%) memiliki kategori nilai 3-4 dan sebanyak 3 orang siswa (10\%) dan memiliki katagori nilai 4-5 dan sebanyak 6 orang siswa (20\%) memiliki katagori nilai 5-6 dan sebanyak 8 orang siswa (27\%) memiliki katagori nilai 6-7 dan sebanyak 6 orang siswa (20\%) memiliki katagori nilai 7-8 dan sebanyak 5 orang siswa (17\%) memiliki katagori nilai 8-9.

Analisis Data

Sebelum melakukan pengujian terhadap hipotesis yang diajukan dalam penelitian ini, maka terlebih dahulu dilakukan uji persyaratan analisis data, yaitu uji normalitas data uji homogenitas varians.

Uji Normalitas Data

Hasil pengujian untuk kelentukan pinggang $\left(X_{1}\right)$ skor Xhitung $=8,11$ dengan $\mathrm{n}$ $=30$ sedangkan Xtabel pada taraf signifikan $\alpha=0,05$ diperoleh 11,070 yang lebih kecil dari Xtabel sehingga dapat disimpulkan bahwa skor yang diperoleh dari kelentukan pinggang berdistribusi normal.

Hasil pengujian untuk power otot lengan $\left(\mathrm{X}_{2}\right)$ skor Xhitung $=8,24$ dengan $\mathrm{n}=30$ sedagkan Xtabel pada taraf signifikan $\alpha=0,05$ diperoleh 11,070 yang lebih kecil dari 
Xtabel sehingga dapat disimpulkan bahwa skor yang diperoleh dari power otot lengan berdistribusi normal.

Hasil pengujian untuk keterampilan Stutz (Y) skor Xhitung $=7,37$ dengan $\mathrm{n}=30$ sedangkan Xtabel pada taraf signifikan $\alpha=0,05$ diperoleh 11,070 yang lebih kecil dari Xtabel sehingga dapat disimpulkan bahwa skor yang diperoleh dari keterampilan Stutz berdistribusi normal.

Uji Homogenitas Varians

Hasil perhitungan varians kelentukan pinggang $\left(X_{1}\right)$ adalah 16, sedangkan varians dari power otot lengan $\left(X_{2}\right)$ adalah sebesar 19,53 dan varians keterampilan Stutz (Y) adalah sebesar 5,15. Maka didapat nilai $F_{\text {hitung }}=3,79$ sedangkan nilai $F_{\text {tabel }}$ pada taraf signifikan $\alpha=0,05$ dengan $\mathrm{dk}=(\mathrm{b}),(\mathrm{n}-1)=(1),(30-1)$ = 1,29dimana 1 sebagai pembilang dan 29 sebagai penyebut adalah sebesar $4,18 F_{\text {hitung }}<F_{\text {tabel }}$ yaitu $3,79<$ 4,18 ini berarti tidak terdapat perbedaan dari masing masing variabel atau harga variansnya Homogen.

Uji Hipotesis

Uji Hipotesis Hubungan Antara Kelentukan Pinggang Dengan Keterampilan Stutz ( $\mathrm{X}_{1}$ Dengan $\mathrm{Y}$ )

Berdasarkann analisi data didapat $r_{\text {hitung }}=0,61$ dan thitung $=$ 4,07. Maka terdapat hubungan yang positif dan signifikan antara kelentukan pinggang dengan keterampilan Stutz.

Dilihat bahwa $r_{\text {hitung }}$ lebih besar dari pada $r_{\text {tabel }}$ dimana rhitung $=0,61>$ rtabel $=0,361$ berarti ada hubungan yang positif antara kelentukan pinggang terhadap keterampilan Stutz. Berdasarkan tabel interprestasi koofesien korelasi berarti tingkat hubungannya berada pada tingkat hubungan yang kuat. Kontribusi kelentukan pinggang terhadap keterampilan Stutz yaitu $\mathrm{K}=$ r2 $\times 100 \%=(0,61)^{2} \times 100 \%$ $=0,3721 \times 100 \%=37,21 \%$. Jadi dapat disimpulkan kantribusi kelentukan pinggang terhadap keterampilan Stutz adalah sebesar 37,21\%.

Mengetahui kualitas keberartian regresi antara variable dilakukan uji " $\mathrm{t}$ ". Dari perhitungan didapatkan nilai $t_{\text {hitung }}=4,07$ dengan $n=$ 30 sedangkan tabel pada taraf signifikan $\alpha=0,05$ diperoleh 2,048 yang lebih besar dari $t_{\text {tabel sehingga dapat }}$ disimpulkan bahwa korelasi antara kelentukan pinggang dengan keterampilan Stutz adalah signifikan.

Uji Hipotesis Hubungan Antara Power Otot Lengan Dengan Keterampilan Stutz ( $\mathrm{X}_{2}$ Dengan $\mathrm{Y}$ )

Berdasarkan analisi data didapat $r_{\text {hitung }}=0,54$ dan $t_{\text {hitung }}$ 
$=$ 3,39. Maka terdapat hubungan yang positif dan signifikan antara power otot lengan dengan keterampilan Stutz

Dilihat bahwa $r_{\text {hitung }}$ lebih besar dari pada $r_{\text {tabel }}$ dimana $r_{\text {hitung }}=0,54>r_{\text {tabel }}=0,361$ berarti ada hubungan yang positif antara power otot lengan keterampilan terhadap Berdasarkan interprestasi Stutz. tabel koofesien korelasi berarti tingkat hubungannya berada pada tingkat hubungan yang sedang. Kontribusi kelentukan pinggang terhadap keterampilan Stutz yaitu $K=r 2 \times 100 \%=(0,54)^{2}$ $\times 100 \%=0,2916 \times 100 \%=$ $29,16 \%$. Jadi dapat disimpulkan kantribusi power otot lengan terhadap keterampilan Stutz adalah sebesar 29,16\%.

Mengetahui kualitas keberartian regresi antara variabel dilakukan uji " $\mathrm{t}$ ". Dari perhitungan didapatkan nilai thitung $=3,39$ dengan $\mathrm{n}=$ 30 sedangkan $t_{\text {tabel }}$ pada taraf signifikan $\alpha=0,05$ diperoleh 2,048 yang lebih besar dari $t_{\text {tabel sehingga dapat }}$ disimpulkan bahwa korelasi antara power otot lengan dengan keterampilan Stutz adalah signifikan.

Uji Hipotesis hubungan Antara Kelentukan Pinggang dan Power Otot Lengan Secara Bersamaan Terhadap
Keterampilan Stutz $\left(X_{1}\right.$ dan $X_{2}$ Dengan Y).

Berdasarkan analisi data tersebut terdapat hubungan yang positif dan signifikan antara kelentukan pinggang $\left(X_{1}\right)$, power otot lengan $\left(X_{2}\right)$ secara bersama - sama terhadap keterampilan Stutz dalam senam lantai pada Siswa SMP Negeri 17 Kota Bengkulu. Pengujian hipotesis ini menggunakan korelasi ganda.

Dilihat bahwa $r_{\text {hitung }}$ lebih besar dari pada $r_{\text {tabel }}$ dimana $r_{\text {hitng }}=0,67>r_{\text {tabel }}=0,361$ berarti ada hubungan yang positif antara kelentukan pinggang dan power otot lengan secara bersama sama terhadap keterampilan Stutz. Berdasarkan tabel interprestasi koofisien korelasi berarti tingkat hubungannya berada pada tingkat hubungan yang kuat. Kontribusi kelentukan pinggang dan power otot lengan secara bersama sama terhadap keterampilan Stutz yaitu $\mathrm{K}=\mathrm{r} 2 \times 100 \%=$ $(0,67)^{2} \times 100 \%=0,4489 x$ $100 \%=44,89 \%$. Jadi dapat disimpulkan kontribusi kelentukan pinggang dan power otot lengan secara bersama - sama terhadap keterampilan Stutz adalah sebesar 44,89\%.

Mengetahui kualitas keberartian regresi antara variabel dilakukan uji"F". Dari perhitungan didapat nilai Fhitung $=11$ dengan $\mathrm{dk}$ n-2 = 
$30-2=28$ sedangkan $F_{\text {tabel }}$ pada taraf signifikan $\alpha=0,05$ diperoleh 4,18 yang lebih besar dari $F_{\text {tabel }}$ sehingga dapat disimpulkan bahwa korelasi antara kelentukan pinggang dan power otot lengan secara bersama sama dengan keterampilan Stutz adalah signifikan.

Hipotesis Kontribusi Antara Kelentukan Pinggang Dan Power Otot Lengan Secara Bersama - Sama Terdapat Keterampilan Stutz ( $\mathrm{X}_{1}, \mathrm{X}_{2}$, Terdapat Y).

Berdasarkan analisis tersebut untuk mengetahui seberapa besar kontribusi kelentukan pinggang $\left(\mathrm{X}_{1}\right)$, power otot lengan $\left(X_{2}\right)$ secara bersama - sama terhadap keterampilan Stutz dalam senam lantai pada Siswa SMP Negeri 17 Kota Bengkulu.

Kontribusi kelentukan pinggang dan power otot lengan secara bersama sama terhadap keterampilan Stutz yaitu $\mathrm{K}=\mathrm{r} 2 \times 100 \%=$ $(0,67)^{2} \times 100 \%=0,4489 \times$ $100 \%=44,89 \%$. Jadi dapat disimpulkan kontribusi kelentukan pinggang dan power otot lengan secara bersama - sama terhadap keterampilan Stutzadalah sebesar 44,89\%.

Berdasarkan hipotesis diatas dapat disimpukan bahwa terdapat kontribusi yang positif antara variabel variabel bebas yaitu kelentukan pinggang $\left(X_{1}\right)$ dan power otot lengan $\left(\mathrm{X}_{2}\right)$ terhadap variabel terikatnya yaitu keterampilan Stutz(Y).

\section{Pembahasan}

\begin{tabular}{lr}
\multicolumn{1}{c}{ Hubungan } & Kelentukan \\
Pinggang & Terhadap \\
Keterampilan & Stutz Dalam \\
Senam Lantai. &
\end{tabular}

Berdasarkan analisis yang dikemukakkan dan dari hasil pengujian hipotesis ternyata diterima kebenarannya bahwa ada hubungan yang positif dan signifikan antara kelentukan pinggang dengan keterampilan Stutz dalam senam lantai. Semakin baik kelentukan pinggang seseorang maka semakin baik pula keterampilan Stutz, dengan demikian seseorang pesenam atau siswa harus memiliki kelentukan pinggang yang baik sehingga menghasilkan keterampilan Stutz yang baik pula.

Hubungan Power Otot Lengan Terhadap Keterampilan Stutz Dalam Senam Lantai.

Berdasarkan hasil dari analisis yang dikemukakan dari hasil penguji hipotesi, ternyata diterima kebenarannya ada hubungan yang positif dan signifikan antara Power Otot Lengan terhadap keterampilan Stutz dalam senam lantai. Semakin kuat power otot lengan maka semakin baik pula keterampilan Stutznya. Power otot lengan merupakan kekuatan otot untuk menerima beban secara maksimal saat bekerja 
terutama sangat diperlukan oleh seorang pesenam atau siswa saat bertumpu atau pun mendorong. Power otot lengan diperlukan untuk mendorong tubuh terangkat ke atas dan kedua kaki menusuk rapat dan runcing.

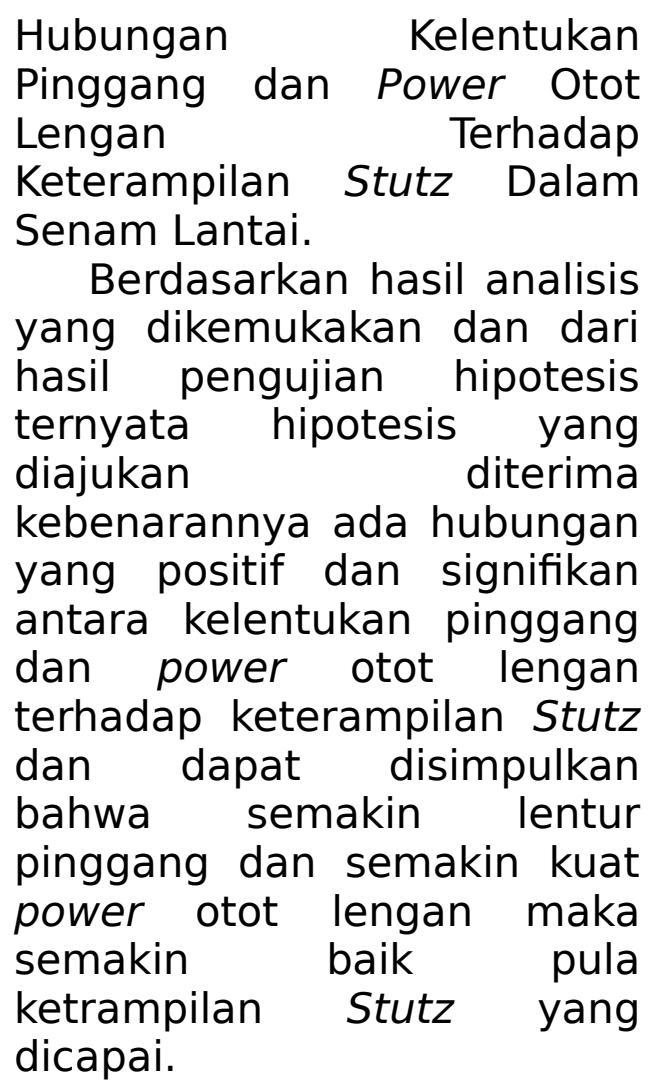

\section{PENUTUP}

\section{Simpulan}

Terdapat hubungan yang positif dan signifikan Kelentukan Pinggang $\left(\mathrm{X}_{1}\right)$ terhadap Keterampilan Stutz (Y) pada Siswa SMP Negeri 17 Kota Bengkulu. Hal ini dibuktikan dengan $r_{\text {hitung }}=$ $0,61>r_{\text {tebel }}=0,361$ dengan taraf signifikan $\alpha=$ 0,05 di dapat $t_{\text {hitung }}=4,07$ $>t_{\text {tabel }}=2,048$. Hal ini berarti kemampuan kelentukan pinggang sangat mempengaruhi hasil dari keterampilan Stutz yaitu untuk mendapatkan hasil gerakan yang baik.

Terdapat hubungan yang positif dan signifikan Power Otot Lengan terhadap keterampilan Stutz pada Siswa SMP Negeri 17 Kota Bengkulu. Hal ini dibuktikan dengan $r_{\text {hitung }}=0,54>$ $r_{\text {tabel }}$ । $=0,361$ dengan taraf signifikasi $\alpha=0,05$ didapat $t_{\text {hitung }}=3,39>t_{\text {tabel }}=$ 2,048. Hal ini berarti power otot lengan sangat mempengaruhi keterampilan Stutz yaitu saat melakukan dorongan yang kuat dan cepat untuk mencapai posisi handstand sesaat.

Terdapat hubungan yang positif dan signifikan antara Kelentukan Pinggang $\left(X_{1}\right)$ dan Power Otot Lengan $\left(X_{2}\right)$ terhadap keterampilan Stutz (Y) pada Siswa SMP Negeri 17 Kota Bengkulu. Hal ini dibuktikan dengan $r_{\text {hitung }}=$ $0,67>r_{\text {tabel }}=0,316$ dengan taraf signifikansi $\alpha=$ 0,05 didapat $F_{\text {hitung }}=11>$ $F_{\text {tabel }}=4,18$. Hal ini berarti kelentukan pinggang dan power otot lengan terhadap keterampilan Stutz, sangat mempengaruhi untuk mendapatkan hasil gerakan yang baik sehingga membutuhkan kekuatan dan kecepatan untuk mencapai posisi handstand sesaat. 
Ada kontribusi antara Kelentukan Pinggang $\left(X_{1}\right)$ dan Power Otot Lengan $\left(\mathrm{X}_{2}\right)$ terhadap Keterampilan Stutz (Y) pada Siswa SMP Negeri 17 Kota Bengkulu yaitu sebesar $44,89 \%$. Hal ini membuktikan bahwa kelentukan pinggang $\left(\mathrm{X}_{1}\right)$ dan power otot lengan $\left(\mathrm{X}_{2}\right)$ terhadap keterampilan Stutz (Y) yang diberikan pada tingkat distribusi sedang dan $55,11 \%$ dipengaruhi oleh faktor lainnya.

\section{Saran}

Bagi dosen atau guru pendidikan jasmani dan olahraga kiranya dapat menganalisa variabelvariabel lain untuk meningkatkan keterampilan Stutz dalam olahraga senam lantai.

Bagi pelatih senam dan guru olahraga agar dapat memberikan materi yang tepat kepada pesenam atau siswa, khususnya untuk melatih kelentukan pinggang dan Power otot lengan yang didukung oleh materi lainnya guna meningkatkan keterampilan Stutz sehingga dapat mendukung dalam menciptakan poin yang mudah.

Bagi Atlet atau mahasiswa agar mengembangkan keterampilan khususnya Stutz analisis yang telah diteliti dalam penelitian ini.

Bagi Peneliti yang ingin melanjutkan penelitian ini agar dapat menjadikan penelitian ini sebagai bahan informasi dan meneliti dengan jumlah populasi atau sampel yang lebih besar serta di daerah yang berbeda.

\section{DAFTAR PUSTAKA}

Arikunto, Suharsimi. (2010). Prosedur Penelitian Suatu Pendekatan Praktik. Jakarta: PT. Rineka Cipta.

Fajriani, Wina Nurasyifa. (2011). Mengenal Senam Alat. Jakarta Timur: PT Wadah Ilmu

Mahendra, Agus. (2001). Pembelajaran Senam Pendekatan Pola Gerak Dominan Untuk Siswa SLTP. Jakarta: Direktorat Jendral Olahraga.

Sugiyono. (2006). Metode Penelitian Kuantitatif, Kualitatif dan $R \& D$. Bandung: Alfabeta.

Tangkudung, James. (2012). Kepelatihan Olahraga Pembinaan Prestasi Olahraga. Jakarta: Cerdas jaya . ,(2016).Macammacam Metodologi Penelitian. Jakarta: Lensa Media Pustaka Indonesia. (2018). Sport Psychometrics Dasardasar dan instrument 
KINESTETIK : Jurnal IImiah Pendidikan Jasmani, 2 (2) 2018

Psikometri. Depok

:Rajagrafindo persada.

Widiastuti. (2011). Tes dan

Pengukuran Olahraga.

Jakarta: PT Bumi Timur

Jaya.

Winarni, Endang Widi. (2011).

Penelitian Pendidikan.

Bengkulu: Unit Penerbitan

FKIP UNIB. 